\section{TREINADORAS E AUXILIARES DO FUTEBOL DE MULHERES NO BRASIL: SUBVERSÃO E RESISTÊNCIA NA LIDERANÇA ESPORTIVA}

\author{
WOMEN'S FOOTBALL COACHES AND ASSISTANT COACHES IN \\ BRAZIL: SUBVERSION AND RESISTANCE IN SPORTS LEADERSHIP C
}

ENTRENADORAS Y AUXILIARES DEL FÚTBOL FEMENINO EN BRASIL: SUBVERSIÓN Y RESISTENCIA EN EL LIDERAZGO DEPORTIVO C

doi' https://doi.org/10.22456/1982-8918.106782

(iD) Mariana Cristina Borges Novais* <maribnovais@hotmail.com>

(iD) Ludmila Mourão*<mouraoln@gmail.com>

iD Osmar Moreira de Souza Junior** <osmar@ufscar.br>

Igor Chagas Monteiro* <igorcmonteiroef@gmail.com>

Bárbara Aparecida Bepler Pires* <barbarabepler@gmail.com>

\footnotetext{
*Universidade Federal de Juiz de Fora. Juiz de Fora, MG, Brasil.

**Universidade Federal de São Carlos. São Carlos, SP, Brasil.
}

\begin{abstract}
Resumo: Fundamentada nos estudos culturais e de gênero, esta pesquisa analisa a representatividade de mulheres em cargos de treinadora e auxiliar no futebol de mulheres, buscando identificar as estratégias de subversão e resistência adotadas para sua inserção e permanência. Os materiais de análise foram os discursos das participantes aliados a fontes documentais, como notícias e produções acadêmicas. A análise evidencia que as profissionais conquistaram o acesso aos cargos em decorrência das experiências como líderes enquanto atletas e/ou estagiárias e por seus altos níveis de capacitação. Elas asseguram sua permanência ao atestarem diariamente sua competência, mantendo o nível de capacitação e superando estereótipos de gênero. Elas personificam a eminente resistência oferecida pelas mulheres em espaços tradicionalmente reservados aos homens, tensionando as relações de poder. Contudo, a consolidação de uma condição equânime requer investimento financeiro e, sobretudo, empenho na desconstrução de estereótipos de gênero.
\end{abstract}

Palavras chave: Divisão de trabalho baseado no gênero. Futebol. Mulheres trabalhadoras. Comportamento estereotipado.
Recebido em: 24 ago. 2020 Aprovado em: 17 fev. 2021 Publicado em: 03 abr. 2021

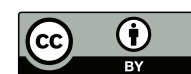

Este é um artigo publicado sob a licença Creative Commons Atribuição 4.0 Internacional (CC BY 4.0). elSSN: 1982-8918 


\section{INTRODUÇÃO}

Durante certo tempo no Brasil, não era permitido às mulheres ampla circulação em espaços públicos, tampouco havia equidade nas condições de acesso ao mundo do trabalho, sendo relegadas a elas as funções do espaço doméstico e os cuidados da maternidade (GOELLNER, 2003). Segundo Coelho (2009) e Goellner (2005), o ambiente esportivo se apresenta como um terreno de afirmação da identidade "masculina" que preserva e reforça as desigualdades culturais entre os gêneros, reproduzindo estereótipos acerca dos papéis desempenhados por homens e mulheres. Nesse sentido, o futebol é terreno fértil para estudos com recorte analítico de gênero, dada sua característica homossocial ${ }^{1}$. Damo (2007, p. 137) afirma que "não é preciso ser especialista para identificar no futebol um predomínio masculino acentuado, seja ele prático ou simbólico"; e considera haver diferentes maneiras de praticar os futebóis, sendo uma delas a matriz espetacularizada, a qual apresenta moldes de caráter monopolista, globalizado e centralizado, além da excelência performática como uma exigência que se impõe de fora para dentro por mediações oriundas de patrocinadores, empresários e interesses do público (DAMO, 2005).

No tocante à participação das mulheres enquanto atletas no esporte em geral, dados $^{2}$ de 2020 mostram que a equidade vem sendo gradativamente alcançada. Não obstante, quando o assunto é a ocupação de cargos de liderança esportiva por elas, a realidade é outra. Estudos elucidam uma baixa representatividade de mulheres líderes no campo esportivo (GOMES, 2006; OLIVEIRA; TEIXEIRA, 2009; PFISTER; RADTKE, 2007; READE; RODGERS; NORMAN, 2009). Ainda hoje, a presença dos homens é predominante na ocupação dos cargos de gestão (TORGA, 2019), na posição de treinador (NOVAIS, 2018), árbitro (MONTEIRO, 2016), narrador e repórter. Sob essa seara, Passero et al. (2020) constataram, através de análise longitudinal, que:

[...] os homens ocupam predominantemente ( $85 \%$ ) os cargos de comissão técnica no Campeonato Brasileiro de Futebol Feminino. A maior inserção das mulheres (22\%) foi encontrada no cargo de auxiliar técnica. Se não houver rupturas no processo de aumento linear e gradual na participação das profissionais nos próximos anos, é possível que a igualdade numérica entre homens e mulheres em cargos de comissão técnica seja alcançada a partir do ano de 2030. (PASSERO et al., 2020, p. 13).

Esse cenário impulsiona a busca por compreender as trajetórias daquelas que almejam construir carreiras profissionais ocupando cargos de liderança no futebol. Ancorada, pois, em uma epistemologia feminista (RAGO, 1998) e fundamentada nos estudos culturais e de gênero, que consideram o conjunto de regras que se

\footnotetext{
1 Homossocial é uma palavra usada às vezes na História e nas Ciências Sociais que descreve vínculos sociais entre pessoas do mesmo sexo; obviamente é um neologismo formado pela analogia de "homossexual", mas também para se distinguir de "homossexual". Na verdade, esta palavra é aplicada a atividades em que há "ligações do sexo masculino", o que pode, numa sociedade, ser caracterizado por intensa homofobia, medo e ódio à homossexualidade (SEDGWICK, 1985, p.1, tradução de FALCÃO; CAMARGO, 2016).

2 A última edição dos Jogos Olímpicos (2016) registrou aumento de 70\% na participação das mulheres brasileiras em relação a 2012 (COMITÊ OLÍMPICO BRASILEIRO, 2017). A delegação brasileira foi composta por 253 homens e 209 mulheres, traduzindo uma representatividade delas de 45,23\%. Para os Jogos Olímpicos de Tóquio, em 03 de abril de 2020, o Brasil contava com 178 vagas confirmadas (COMITÊ OLÍMPICO BRASILEIRO, 2020), das quais, no mínimo, 83 conquistadas por mulheres (46,62\%). Além disso, em dois esportes coletivos, o Brasil será representado, até então, somente pelas mulheres: Handebol e Rugby Sevens.
} 
articulam em prol da manutenção da heteronormatividade ${ }^{3}$ um dos possíveis desafios a essas mulheres, esta pesquisa analisa os processos de inserção e permanência de treinadoras de futebol e auxiliares em comissões técnicas, visando identificar a existência de dificuldades relacionadas às questões de gênero durante a construção de suas carreiras.

Discussões sobre essa categoria acarretam debates acerca das relações de poder ${ }^{4}$ estabelecidas histórica e culturalmente entre homens e mulheres (NORONHA, 2016). Portanto, a opção por trabalhar o gênero enquanto categoria analítica baseia-se no entendimento de que o esporte é uma construção cultural à qual se agregam discursos, valores e práticas que acabam marcando representações de feminilidades e masculinidades que definem, também, posições sociais (GOELLNER; KESSLER, 2018). As representações de feminilidade rígidas sustentadas no conceito heteronormativo e os discursos sobre o que é ou não "papel de mulher" nessa sociedade estão imbricados nas oportunidades de acesso das mulheres a determinados ambientes, práticas corporais e postos de trabalho no esporte brasileiro.

Este artigo busca, portanto, conferir visibilidade às trajetórias das treinadoras e auxiliares do futebol de mulheres no Brasil, elucidando possíveis causas associadas à baixa representatividade. $O$ estudo se justifica por nos permitir compreender como tais trajetórias contribuem para ressignificar e reconstruir as relações de gênero dentro das comissões técnicas, evidenciando estratégias de subversão e resistência no campo da liderança esportiva.

\section{O FUTEBOL DE MULHERES NO BRASIL}

Parte dos dados que compõem nosso empreendimento datam de 2016, quando teve início nossa investigação. Esse ano foi marcado por acontecimentos esportivos e políticos ${ }^{5}$ que guardam estreita relação com nosso objeto de estudo. Conforme afirma Goellner (2007):

Adotar como objeto de investigação as mulheres, os esportes e suas
historicidades é, sem dúvida alguma, uma opção individual e está permeada
por significações que cada autor/a empreende ao seu esforço investigativo.
É ainda político porque circunscrito ao ambiente acadêmico, onde
temáticas como essas se encontram, muitas vezes, nas zonas de sombra,
sendo responsabilidade do/a pesquisador/a trazê-las à luz, conquistar
espaços, atribuir-lhes sentidos. Político também porque pesquisar implica
fazer opções epistemológicas e metodológicas e estas nunca são neutras,
a-históricas, muito menos universalistas. (GOELLNER, 2007, p. 173-174).

\footnotetext{
3 Norma que articula as noções de gênero e sexualidade, estabelecendo como natural certa coerência entre sexo (nasceu macho, nasceu fêmea), gênero (tornou-se homem, tornou-se mulher) e orientação sexual (se é um homem, irá manifestar interesse afetivo e sexual por mulheres, e vice-versa) (SEFFNER, 2013, p. 150).

4 É necessário desvincular o poder das estruturas políticas, governos e instituições repressoras que supostamente o exercem sobre os subordinados, para refletir sobre a existência de micropoderes ascendentes presentes em qualquer relação humana (FOUCAULT, 1987).

5 Foi tempo de um cenário aparentemente favorável ao futebol de mulheres, no que tange a ações promotoras, à criação de um Comitê de Reformas dentro da CBF, à nomeação de Emily Lima como a primeira mulher treinadora da Seleção Brasileira de futebol de mulheres (após três décadas de comando masculino) e à visibilidade proporcionada para a modalidade em função dos Jogos Olímpicos sediados no Brasil. Por outro lado, o mesmo momento históricopolítico foi marcado pelo golpe misógino aplicado pelo Governo, no qual a presidenta eleita legitimamente, Dilma Rousseff, teve seu mandato cassado (em 31 de agosto de 2016) após longo e controverso processo no Congresso Nacional. Controversa, repentina e injustificada foi também a demissão de Emily Lima.
} 
Por essas razões, adotamos o termo "futebol de mulheres" em detrimento de "futebol feminino" com base nas reflexões propostas por Kessler (2015). A autora defende uma mudança no olhar sobre esse universo com o objetivo de contemplar a diversidade presente nos mundos futebolísticos de mulheres:

O termo futebol de mulheres se relaciona a um universo complexo e heterogêneo, permeado por trocas entre pessoas de diferentes classes, etnias, gêneros e religiosidades, no interior desta coletividade. Ou seja, entendo o termo 'mulheres' como abrangendo corpos e subjetividades de sujeitos que não são neutros, abstratos e nem universais. (KESSLER, 2015, p. 32).

O futebol de mulheres no Brasil conta, hoje, com um campeonato oficial em nível nacional organizado pela Confederação Brasileira de Futebol (CBF): o Campeonato Brasileiro de Futebol Feminino ${ }^{6}$, que se divide em duas séries desde 2017, após ter passado por reformulação ${ }^{7}$. No ano de início desta investigação, ainda era disputada também a Copa do Brasil.

O cenário estabelecido em torno do futebol de mulheres em 2016 levou a Federação Internacional de Futebol (FIFA) a lançar uma ação global para sua valorização. Quando iniciamos as entrevistas com nossas colaboradoras, havia uma expectativa positiva em suas narrativas quanto à entrada em vigor de medidas que obrigariam os clubes de futebol masculino a manterem equipes de mulheres a partir de 2019. Essas medidas, fomentadas pela ação da FIFA, foram materializadas em forma de licenciamentos ${ }^{8}$ pela Confederação Sul-Americana de Futebol (CONMEBOL). $\mathrm{O}$ teor das medidas determinou que os times masculinos que almejassem continuar disputando a Copa Libertadores da América e a Copa Sul-Americana mantivessem equipes de futebol de mulheres adulta e juvenil. A CBF acompanhou o fluxo continental e decidiu que, para continuarem a disputar a Série A do Campeonato Brasileiro de Futebol Masculino, os clubes deveriam seguir as mesmas diretrizes. Em 2019, os licenciamentos entraram em vigor e o futebol de mulheres viveu um momento histórico durante a Copa do Mundo:

A competição bateu recorde de audiência: de acordo com um relatório da Fifa, foram 1,12 bilhão de espectadores ao redor do mundo - somando público de TV e de internet - o que representa um aumento de $30 \%$ se comparado à edição média registrada no Mundial de 2015, no Canadá. (RODRIGUES, 2019).

Esse conjunto de fatores impactou positivamente a oferta de oportunidades de trabalho para mulheres nas comissões técnicas, mas não garantiu aumento significativo de sua representatividade na ocupação de cargos de treinadoras e auxiliares. Apresentaremos alguns dados percentuais e, embora o quantitativo

\footnotetext{
6 Será mantido "feminino" nessa situação por ser a nomenclatura oficial.

7 Era composto de série única e disputado por 20 equipes selecionadas segundo critérios expostos no regulamento específico. A partir de 2017, houve a divisão em duas séries (A1 e A2), compostas por 16 e 36 times, respectivamente, havendo acesso e descenso. A Copa do Brasil era disputada por 32 clubes.

8 A FIFA trabalha com o licenciamento de clubes desde 2007, a fim de elevar o nível das competições e dos clubes no âmbito mundial, podendo cada confederação adaptar o sistema às suas necessidades locais, via regulamento próprio, gerando impacto positivo nas diversas áreas técnicas e administrativas dos clubes e de infraestrutura. No futebol sul-americano, a CONMEBOL incorporou o licenciamento de clubes no ano de 2016. A partir daí, em relação às competições continentais de clubes, a CBF reconhece a autoridade da CONMEBOL para estabelecer licenças próprias. Por delegação da CONMEBOL, caberá à CBF atuar diretamente junto aos clubes brasileiros, como ente concedente e de monitoramento das licenças aplicáveis a referidos certames internacionais (PINHEIRO, 2017).
} 
desvele que as mulheres estão sub-representadas, a pesquisa é de abordagem qualitativa com ênfase na descrição, na indução, na teoria fundamentada e no estudo das percepções pessoais (MINAYO, 2007). Por esses meios, buscamos compreender os sentidos e significados do objeto de estudo a partir da perspectiva e dos discursos das participantes, aliados a fontes documentais.

Colaboraram com a pesquisa nove treinadoras e auxiliares que compuseram comissões técnicas de equipes brasileiras do futebol de mulheres em $2016^{9}$. Elas foram encontradas mediante consulta às súmulas oficiais dos jogos disponíveis no site da CBF, e as entrevistas foram realizadas via chamada de vídeo pelo Facebook, recurso de áudio no WhatsApp e ligação telefônica. Esses recursos não comprometem a coleta dos dados, sendo já reconhecidos e amplamente utilizados nesse campo de pesquisa (FÉLIX, 2014). Os áudios foram gravados e o processo de transcrição seguiu o Manual Básico de Transcrição ${ }^{10}$ do Centro de Memória do Esporte (CEME).

O diálogo entre as fontes foi desenvolvido por meio da Análise de Conteúdo (BARDIN, 1977). Utilizamos, especificamente, a técnica de Análise Temática (MINAYO, 2007), cujo foco recai sobre a qualificação das vivências do sujeito e suas percepções acerca de determinado objeto ou fenômeno, conferindo, portanto, voz e visibilidade a quem é protagonista quando o assunto é a representatividade de mulheres como treinadoras e auxiliares.

Considerando esses pressupostos teórico-metodológicos e diante do material coletado e analisado, destacaremos duas categorias para aprofundamento: as trajetórias de treinadoras e auxiliares do futebol de mulheres no Brasil, elucidando possíveis causas associadas à baixa representatividade nesses cargos; e as estratégias de subversão e resistência das quais dispõem para permanecerem no campo da liderança esportiva.

\section{TREINADORAS E AUXILIARES: TRAJETÓRIAS E QUESTÕES ASSOCIADAS À BAIXA REPRESENTATIVIDADE}

O futebol é ainda um esporte liderado e protagonizado por homens, mas não há dúvidas de que as mulheres vêm explicitando seu potencial de subversão ao romperem barreiras impostas à inserção em cargos de liderança (NOVAIS, 2018). Compartilhando os pressupostos de Goellner e Kessler (2018, p. 33), partimos da premissa de que "[...] conhecer histórias e trajetórias de mulheres é fundamental para reconhecer seu protagonismo na modalidade". Ainda que a representatividade de mulheres treinadoras e auxiliares no próprio futebol de mulheres seja baixa, aquelas que chegam a ocupar esses cargos o fazem mediante investimento em capacitação, bem como em função do bom desempenho apresentado como atletas e/ou profissionais de Educação Física (NOVAIS, 2018). Assim, cabe-nos conferir visibilidade a essas trajetórias e buscar compreender os fatores associados à baixa representatividade.

\footnotetext{
9 Sete entrevistas foram colhidas em 2016 e duas ocorreram em 2017. O critério de inclusão no estudo foi a ocupação do cargo de treinadora ou auxiliar no Campeonato Brasileiro e/ou na Copa do Brasil de 2016.

10 Documento de uso interno do CEME, que à época se encontrava disponível on-line na aba do projeto intitulado "Garimpando Memórias":
} 
Começando pelo pilar da visibilidade, procederemos à caracterização das colaboradoras. A média de idade é de aproximadamente 34 anos. A maioria declarou praticar esportes desde a infância e relatou ter começado a prática do futebol nessa mesma fase; sete delas seguiram praticando futebol ou futsal durante a adolescência, além de atuarem em clubes e escolinhas, até chegarem à condição de atletas de rendimento na vida adulta. Essa característica foi fator propulsor em suas carreiras até as comissões técnicas. No que concerne à etnia, duas se autodeclararam negras, duas, pardas e as outras cinco, brancas. Quanto à nacionalidade, oito são brasileiras e uma é chilena, característica que acreditamos ter papel importante em sua trajetória, uma vez que suas respostas evidenciaram o quanto a cultura em que foi educada produz representações distintas sobre as mulheres no futebol e, por conseguinte, influencia suas trajetórias pessoais e profissionais. Em relação ao estado civil, oito se declararam solteiras e uma, casada. Quanto à maternidade, nenhuma delas era mãe.

Somente duas trabalham nas comissões técnicas do futebol de mulheres com dedicação exclusiva. As demais relatam acumular ocupações para subsistirem, na medida em que a profissão de treinadora ou auxiliar não se encontra bem estruturada em diversos aspectos, principalmente no tocante à remuneração.

Todas são, no mínimo, graduadas em Educação Física. Seus níveis de capacitação ocuparão lugar de destaque nas discussões a posteriori.

As trajetórias das treinadoras e auxiliares apresentam homogeneidade em relação ao envolvimento com o esporte desde a infância e com o futebol e/ou futsal, especificamente, na condição de atletas. É consenso na literatura a existência de relações entre infância ativa e envolvimento com a gestão e a prática de esportes na vida adulta (FERREIRA, 2012; PISANI, 2012; FERNANDES, 2014) e que as meninas vão subjetivando desde crianças suas relações com a bola, o corpo e os esportes, construindo atitudes e comportamentos vigorosos e desafiadores. Especificamente sobre o futebol/futsal, mais da metade das entrevistadas alega ter iniciado o contato com a modalidade brincando na rua com meninos ou nas aulas de Educação Física.

\footnotetext{
Joguei como a maioria das meninas começou, na escola, jogando nas aulas de Educação Física. Naquele momento em que os professores mandavam as meninas para um lado e os meninos para o outro, eu sempre ia para o lado dos meninos [risos] (Luana Paula ${ }^{11}$, auxiliar, 32 anos).
}

Eu comecei a brincar de futebol com os meus primos em casa, no terraço de casa, na garagem e depois minha avó... A minha família acabou me liberando para brincar na rua com eles [...] (Thaissan Passos, auxiliar, 31 anos).

Narrativas como a de Thaissan, quando diz que a família "acabou liberando", denotam certa resistência quanto ao seu envolvimento nessa prática; a fala de Luana também evidencia o fato de não ser natural, nem mesmo na escola, a vivência do futebol pelas meninas. Sem dúvida, os estímulos e os discursos acessados no ciclo familiar são mais influenciadores do que propriamente a aula de Educação Física. Até que cheguem à idade escolar, as meninas tendem a frequentar outros espaços

11 Os nomes das entrevistadas são reais e sua divulgação foi autorizada. Para mais informações, consultar parecer emitido pelo Comitê de Ética em Pesquisa Humana da UFJF, n. protocolo 1.947.687. 
que reforçam os estereótipos de gênero, e é em função do que é permitido ou não a elas que significam essa prática.

Damo (2006, p. 1) buscou "mostrar [...] a maneira como o jogo se presta para dramatizar determinados códigos éticos e estéticos associados ao masculino e ao feminino" ao analisar a realidade da rua, trazendo como principal argumento o fato de o futebol ser um jogo culturalmente definido como masculino e masculinizante. Com olhar centrado na dinâmica do grupo, concluiu que o futebol é praticado por razões de ordem simbólica e que, nessa dimensão, não se valoriza somente a habilidade motora, mas também a coragem e a virilidade. Portanto, as colaboradoras que, ainda crianças, ocupam o espaço da rua e apresentam coragem para o "jogo duro" são vistas pelos meninos como "iguais". Isso reverbera num aspecto frequentemente observado em trajetórias esportivas de mulheres: a participação de agentes facilitadores (BOURDIEU, 2005) nos processos de início e continuidade delas no esporte, ou seja, pessoas que compartilham espaços de sociabilidade e buscam viabilizar suas pretensões. Quando questionadas sobre receberem esse apoio e incentivo, duas colaboradoras relataram não os terem recebido; e, dentre as repostas positivas, o incentivo foi oriundo predominantemente de homens e, por vezes, se deu com ressalvas por parte de alguns familiares:

Eu tinha meu pai que me incentivou muito. Mas quem mais me dava incentivo era o técnico que eu tinha no projeto [...]. Minha família foi bem pouco (Fabiana Guedes, treinadora, 32 anos).

[...] tinha mais [incentivo] do irmão, assim [...]. Minha mãe não. Minha mãe já não curtia muito não (Talita Oliveira, auxiliar, 27 anos).

Nesses casos, o pai, o irmão e o treinador se constituem nos agentes pertencentes ao capital social delas, que agiram no sentido de ampliar suas possibilidades de circulação e ascensão (BOURDIEU, 2005) no terreno do futebol. Porém, não se trata de atribuir responsabilidade ou mérito aos homens, mas sim de apontar para as negociações constantes que permeiam as relações sociais. Nesse sentido, as treinadoras e auxiliares que jogam bola desde a infância resistiram e empreenderam manobras para seguirem no âmbito do futebol; uma delas é a apresentação de atributos valorizados pela dimensão simbólica do jogo. Todavia, lembrando que o jogo é tido como "masculino e masculinizante", enfrentam desafios constantes relacionados às questões de feminilidade. Algumas narrativas demonstraram como as próprias mulheres significam a feminilidade e o papel social atribuído a si, de modo a reproduzirem estereótipos na educação das filhas ou as próprias meninas se limitarem a eles:

[...] eu tinha medo porque a minha mãe tinha um salão de beleza, ela tentou me colocar no balé [...], mas ela nunca me proibiu. Eu que tinha medo de frustrar a minha mãe. [...] Então assim, não é que minha mãe tinha preconceito. Eu que tinha medo de não ser para minha mãe o que ela gostaria que eu fosse, entendeu? (Thaissan Passos, auxiliar, 31 anos).

Numa concepção hegemônica de feminilidade, a "verdadeira mulher", para além do sexo biológico, é aquela cujo corpo traduz os padrões de beleza e vaidade concebidos socialmente. Conforme constatou Goellner (1999, p. 49), "[...] para ser belo o corpo da mulher deve ser forte, ágil, harmonioso e atlético. No entanto, não pode 
deixar de ser gracioso, delicado e fértil [...]". As atitudes da mãe e da adolescente, à época, traduzem suas tentativas de corresponder ao ideal de mulher feminina. Isso requer não somente adequar o corpo às regras, como também adequar suas práticas corporais a essas regras.

Buscando compreender que representações as pessoas tinham sobre as treinadoras e auxiliares enquanto ainda praticantes do futebol, indagamos sobre o que costumavam ouvir:

Mulher é sexo frágil e não dá para jogar futebol (Neila Rosas, treinadora, 49 anos).

Na minha época [risos] era mulher macho, macho-fêmea, sapatão [...] (Gleide Costa, treinadora, 40 anos).

É unânime a menção da ocorrência de atos preconceituosos de ordem verbal. Constantemente ouviam comentários sobre "sexo frágil", xingamentos atrelando-as ao que se tem estabelecido como "masculino" e, por consequência, insinuações e suspeições sobre sua sexualidade. Por não se configurarem como objeto de nossas análises, não indagamos às colaboradoras questões sobre sexualidades, bem como não aprofundamos discussão acerca do estado civil e da maternidade. Entretanto, assim como o passado na condição de atletas se relaciona diretamente com suas carreiras, esses dois pontos influenciam o modo como vivenciam a rotina de trabalho. Os padrões de feminilidade abarcam não só os atributos e comportamentos colocados por Goellner (1999), mas, também, as escolhas e os caminhos a serem seguidos, como o matrimônio e o desejo de ser mãe. As colaboradoras subvertem essas ideias na medida em que vivem e seguem suas carreiras solteiras, não significando ausência de feminilidade, mas sim ressaltando mais uma possibilidade dentro das inúmeras feminilidades a serem manifestadas. Ferreira et al. (2013) concluíram que manter a carreira de treinadora e uma família, sendo mães ou não, é tarefa difícil para as mulheres, haja vista as características do trabalho desempenhado e o modo como as relações de gênero se estabelecem no cotidiano doméstico.

Os preconceitos extrapolam as questões de feminilidade e sexualidade, buscando reforçar a noção de que o esporte - e posteriormente o treinamento - não é tarefa para mulheres. A associação do treinamento à figura masculina ainda é obstáculo para a aceitação das mulheres como técnicas (NORMAN, 2010). Sobre os meios pelos quais se inseriram nas comissões, as colaboradoras relataram que as características de liderança e inteligência técnica/tática apresentadas dentro de campo/quadra foram determinantes:

[...] eu sempre procurava orientar a equipe, sempre gostava de me aprofundar nessa área, então eu desde cedo pegava alguns treinadores que eram mais inteligentes e que tinham uma bagagem maior, eles me falavam: 'Oh, tu tem potencial para ser treinadora.' (Patrícia Gusmão, treinadora, 38 anos).

Não somente os atributos relacionados à liderança somados à experiência enquanto jogadoras garantiram o acesso às comissões técnicas. Aquelas que não tiveram oportunidades oriundas de seus desempenhos dentro das quatro linhas se dedicaram aos estágios e aos estudos. 
Era um curso de quarenta pessoas, só três mulheres e duas não continuaram, aí eu continuei e comecei a me destacar, sabe? Aí meus professores, eles mesmos me colocaram para fazer os estágios em um clube (Macarena Celedon, treinadora, 30 anos).

[...] eu resolvi que eu ia estudar e me focar no esporte [...]. E aí eu fui fazer faculdade de Educação Física no Sul mesmo e logo no primeiro semestre do curso, já sabendo a área que eu queria, que era o futebol, todos os cursos que eu pude fazer sempre corri atrás para poder fazer [...] (Michele Kanitz, auxiliar, 26 anos).

A combinação entre ser ex-atleta e realizar a formação na área da Educação Física conferiu às colaboradoras um diferencial para atuação nos cargos, na medida em que conseguem associar a experiência do jogo à formação acadêmica e, por essas razões, protagonizam a abertura de portas para inserção nas comissões técnicas. Observamos que treinadores e dirigentes do futebol de mulheres no Brasil interpretam a competência para o exercício da liderança das equipes desatrelada do sexo e, contrariando o princípio da similitude (KILTY, 2006), convidam e contratam mulheres para atuar nos clubes com base em suas performances físicas, intelectuais e comportamentais. No entanto, eles são minoria. Ainda circunda esse campo o paradigma a partir do qual se espera das mulheres o envolvimento com atividades de cuidado, receptividade e acolhida, enquanto dos homens espera-se o exercício da liderança e tomada de decisões (ROMERO, 2009).

Sendo o esporte, e sobretudo o futebol, um campo profícuo à produção e demonstração de uma masculinidade hegemônica (CONNELL; MESSERSCHMIDT, 2013), ainda que a categoria gênero seja usada como um argumento que situa as mulheres em condição hierarquicamente inferior no interior das relações de poder, as colaboradoras mostram que sua aptidão para a ocupação de cargos de liderança se deve à constante busca por qualificação e experiências que culminam na competência necessária. Não obstante, assim como relataram Jaeger et al. (2010), no Brasil, as questões de ordem simbólica sobre o futebol e a feminilidade implicam significativamente uma baixa representatividade das mulheres em comissões técnicas.

Levando em consideração o ano de 2016, 15 treinadoras e auxiliares foram identificadas num universo de 45 equipes (somatório de equipes participantes do Campeonato Brasileiro e da Copa do Brasil, após subtrair sete equipes que disputaram ambos concomitantemente). Em uma situação ideal, se cada equipe contasse com um(a) treinador(a) e mais um(a) auxiliar, dois cargos seriam ocupados por pessoas diferentes e o quantitativo de profissionais atuantes chegaria a 90. Dessa forma, o número absoluto de 15 treinadoras/auxiliares corresponde a uma representatividade de $16,66 \%$. Para o ano de 2017, com a alteração do formato do Campeonato Brasileiro e a extinção da Copa do Brasil, apesar do aumento do número de equipes envolvidas, a representatividade de mulheres ocupando cargos de treinadoras ou auxiliares foi de apenas $5,76 \%$ (seis mulheres: quatro treinadoras, sendo duas de cada série; e duas auxiliares da série A2).

A maioria das mulheres, ao serem indagadas sobre as perspectivas de mudanças nesse cenário, apostou em melhorias. Algumas foram mais precisas 
ao mencionarem que a crença em um maior desenvolvimento da modalidade se sustentava pela expectativa em torno do licenciamento criado pela CONMEBOL. Entretanto, no seu primeiro ano de vigor, a representatividade de treinadoras e auxiliares nas duas séries do Campeonato Brasileiro 2019 foi de 15,38\% (16 mulheres), não superando significativamente o observado em 2016.

$\mathrm{Na}$ tentativa de explicar o decréscimo, ainda que sutil, na representatividade de mulheres treinadoras, mesmo diante do cenário otimista que se estabeleceu, podemos destacar duas possibilidades. Uma delas é o fato de que as mudanças realizadas pela CBF no ano de 2017 fizeram com que clubes tradicionais no futebol de mulheres se desestruturassem. A outra se relaciona à chegada dos "clubes de camisa" e seus interesses se voltarem apenas ao cumprimento do licenciamento frente a um curto tempo para adaptações e investimentos que não necessariamente mantiveram ou melhoraram as condições de trabalho, a remuneração e a prática para as mulheres.

Em 2020, com o formato do Campeonato Brasileiro preservado, encontrou-se representatividade de $20,19 \%$. São 21 mulheres (duas treinadoras na série $A 1$ e seis na A2; quatro auxiliares na série $A 1$ e nove na $A 2$ ). Essa é a maior taxa registrada desde $\mathrm{o}$ ano em que iniciamos os estudos, conforme foi também constatado por Passero et al. (2020). Chamam atenção os números absolutos de auxiliares presentes nas comissões, e isso atenta os(as) pesquisadores(as) da área para a necessidade de elaboração de estudos que busquem elucidar as razões, a fim de que a representatividade das auxiliares cresça de modo mais acelerado que a das treinadoras.

\section{ESTRATÉGIAS DE SUBVERSÃO E RESISTÊNCIA NO CAMPO DA LIDERANÇA ESPORTIVA}

As treinadoras e as auxiliares do futebol de mulheres no Brasil investem em capacitação para conquistarem o acesso ao cargo; todas possuem formação superior em Educação Física e a maioria concretizou especializações ou cursos mais breves voltados ao futebol e ao treinamento. É possível afirmar que a competência e o alto investimento em capacitação refletiram e refletem diretamente nas vias de acesso aos cargos, quais sejam: formação superior, convite pessoal feito por dirigentes/ treinadores, estágios em clubes e trabalhos desenvolvidos em escolinhas.

Superado o momento da inserção, quando questionadas sobre o que seria fundamental para garantir a permanência da mulher como treinadora ou auxiliar, ratificam que se trata de continuar a estudar:

O primeiro é estudar. Se preparar. Não adianta ter sido uma muito boa jogadora para ser uma boa técnica [...] (Macarena Celedon, treinadora, 30 anos).

Me capacitar. Eu tenho gana de estudar, de fazer curso, de me preparar, de fazer estágio [...] (Thaissan Passos, auxiliar, 31 anos).

Conquistar o direito à ocupação dos cargos analisados em função de seu desempenho no meio do futebol, aliado a todo empenho na qualificação, configura uma 
potente estratégia de resistência e subversão do cenário de sub-representatividade. Todas elas destacam as experiências práticas, as capacitações extras, bem como a formação superior, como primordiais:

[...] eu fiz algumas capacitações [...] e alguns cursos no Sul mesmo e nesse meio do processo, durante a faculdade, eu ingressei a fazer a Licença $C$ da CBF. Fiz a Licença B no outro ano, fiz Análise de Desempenho também. Agora eu estou concluindo um de especialização em futebol na UFV, em Minas Gerais [...] (Michele Kanitz, auxiliar, 26 anos).

[...] tive oportunidade de ganhar uma bolsa da CBF para fazer a Licença C. Infelizmente os custos do curso são bem altos, a gente precisa se programar bastante para conseguir fazer [...] (Thaissan Passos, auxiliar, 31 anos).

O custo das licenças é alto ${ }^{12}$ e é notório que o futebol de mulheres no Brasil não desfruta de investimentos tão altos quanto o futebol de homens disputado em nível profissional e escala nacional.

É uma carreira que está se iniciando. A de treinadora de futebol feminino [...]. É diferente do futebol masculino. [...] Infelizmente a gente tem que trabalhar em outras situações para poder trabalhar no futebol feminino. É muito pouco pelo que eu também acompanho e já tive propostas também de outros clubes e é incompatível. [...] (Gleide Costa, treinadora, 40 anos).

Além disso, não havia, de forma bem estabelecida e na realidade das entrevistadas, nesta investigação, uma cultura de investimentos dos clubes na capacitação de sua equipe de profissionais. Destarte, as treinadoras que se capacitam no mais alto nível plausível no Brasil o fazem por méritos próprios e diante de uma situação financeira desfavorável ou até mesmo precária: a remuneração é baixa, a necessidade de trabalhar em mais de um emprego é latente e o tempo dedicado à profissão é extenuante. Ainda assim, elas afirmam que a possibilidade de acesso e permanência no cargo é fruto da dedicação aos estudos e, por isso, não medem esforços nessa direção (NOVAIS, 2018).

Além disso, questionamos o fato de se exigir das mulheres (ainda que não de forma legal) uma formação específica para o treinamento, porém tal necessidade não é imposta aos homens. Nem mesmo existe a obrigatoriedade de formação em Educação Física ao indivíduo que pleiteia o cargo de treinador ou auxiliar. Isso culmina em falas lamentáveis, como a do treinador Renato Gaúcho:

Quem precisa aprender, estuda, vai pra Europa... Quem não precisa vai pra praia. Eu falo isso, e muitos criticaram. Disseram: estão trazendo um treinador que estava jogando futevôlei... Eu pergunto, e agora? E aí? Futebol é como andar de bicicleta. Quem sabe, sabe. Quem não sabe, vai estudar. (WERNEK; SALDANHA, 2016).

Dezenas de treinadores atuam sem nenhuma formação, muitas vezes pelo simples fato de terem sido bons atletas; tampouco a competência desses homens é colocada em suspeição, pois seu sexo parece ser um passaporte legítimo para desempenho da função. Em reportagem da Folha UOL, Cosenzo (2017) afirma que, se a formação mínima como profissional de Educação Física fosse requisitada, apenas nove dentre os vinte treinadores atuantes na série $A$ do Campeonato

12 A Licença C habilita para o trabalho em escolas de futebol a um custo de $R \$ 4.480,00$. As demais licenças, $B(R \$$ $6.170,00), A(R \$ 8.840,00)$ e Pró $(R \$ 19.130,00)$, respectivamente, habilitam para categorias de base e profissional. Mais informações disponíveis em: https://www.cbf.com.br/cbfacademy/pt-br/cursos?categoria=1. Acesso em: 11 jan. 2021. 
Brasileiro masculino poderiam continuar trabalhando. Esse dado aponta para a lacuna existente no que tange à formação/capacitação dos homens treinadores no Brasil. Em contrapartida, ainda que as mulheres venham se apresentando cada vez mais qualificadas, sua representatividade não acompanha direta e proporcionalmente sua qualificação.

\section{CONSIDERAÇÕES FINAIS}

A baixa representatividade de mulheres em cargos de liderança esportiva é consideravelmente analisada. Ainda é notável a predominância dos homens ocupando funções de líderes, ratificando a característica generificada do esporte e seu potencial para a reprodução de estereótipos e representações sociais sobre os lugares ocupados e papéis desempenhados por homens e mulheres.

Ainda que persista um esforço, velado ou não, de manter a hegemonia dos homens no futebol e marginalizar as mulheres, relegando sua atuação profissional às categorias de base e formação esportiva, colocando em suspeição suas feminilidades e sexualidades, questionando sua competência para a liderança e desvalorizando financeiramente seu trabalho, as treinadoras e auxiliares entrevistadas personificam a eminente resistência oferecida pelas mulheres em espaços histórica e socialmente reservados aos homens, na medida em que dispõem de estratégias eficientes para tensionar as relações de poder estabelecidas e conquistar o acesso aos cargos por meio de suas próprias manobras.

Contudo, faz-se necessário promover ações mais efetivas voltadas ao futebol de mulheres que reverberem no devido reconhecimento e na visibilidade do protagonismo de mulheres como as treinadoras e auxiliares deste estudo, além de investimentos que possam garantir condições equitativas para a capacitação, inserção e permanência delas no campo da liderança esportiva. A condição equânime requer investimento financeiro, mas, sobretudo, empenho na desconstrução de estereótipos de gênero que imputam às mulheres responsabilidades sociais que podem se configurar como obstáculos em suas trajetórias.

\section{REFERÊNCIAS}

BARDIN, Laurence. Análise de conteúdo. Lisboa: Edições 70, 1977.

BOURDIEU, Pierre. A economia das trocas simbólicas. 6. ed. São Paulo: Perspectiva, 2005.

COELHO, Juliana. Voleibol: um espaço híbrido de sociabilidade esportiva. In: TOLEDO, Luiz Henrique; COSTA, Carlos Eduardo (org.) Visão de jogo: antropologia das práticas esportivas. São Paulo: Terceiro Nome, 2009. cap. 3, p. 75-93.

COMITÊ OLÍMPICO BRASILEIRO. Time Brasil: nos jogos Olímpicos Rio 2016, o Time Brasil levará a maior delegação da sua história. [2017]. Disponível em: https://agenciabrasil. ebc.com.br/rio-2016/noticia/2016-07/com-462-atletas-brasil-competira-com-maiordelegacao-de-sua-historia . Acesso em: 27 jan. 2018. 
COMITÊ OLÍMPICO BRASILEIRO. Vagas confirmadas para o Time Brasil nos Jogos Olímpicos Tóquio 2020. [2020]. Disponível em: https://www.cob.org.br/pt/toquio-2020/ vagas-confirmadas. Acesso em: 03 abr. 2020.

CONNELL, Robert; MESSERSCHMIDT, James. Masculinidade hegemônica: repensando o conceito. Revista de Estudos Feministas, v. 21, n. 1, p. 241-282, abr. 2013.

COSENZO, Luiz. Só 9 técnicos da Série A poderiam ficar no cargo em 2019 com nova regra. Folha de S. Paulo, maio 2017. Disponível em: http://www1.folha.uol.com.br/ esporte/2017/05/1888487-so-9-tecnicos-da-serie-a-poderiam-continuar-no-clube-com-novaregra.shtml. Acesso em: 16 mar. 2018.

DAMO, Arlei Sander. A dinâmica de gênero nos jogos de futebol a partir de uma etnografia. Revista Gênero, v. 7, n. 2, p. 137-152, 2007.

DAMO, Arlei Sander. As dramatizações do gênero numa configuração futebolística. In: SEMINÁRIO FAZENDO GÊNERO: Práticas corporais e esportivas, 7, Florianópolis. Anais... Florianópolis: UFSC, 2006. p. 1-7.

DAMO, Arlei Sander. Do dom à profissão: uma etnografia do futebol de espetáculo a partir da formação de jogadores no Brasil e na França. 2005. 435 f. Tese (Doutorado em Antropologia Social) - Instituto de Filosofia e Ciências Humanas, Universidade Federal do Rio Grande do Sul, Porto Alegre, 2005.

FALCÃO, Maria de Fátima; CAMARGO, Flávio Pereira. Humilhados e ofendidos: o internato enquanto espaço de homossociabilidade. Revista Literatura em Debate, v. 10, n. 18, p. 88105, ago. 2016. Disponível em: http://revistas.fw.uri.br/index.php/ literaturaemdebate/article/ view/2149/2130. Acesso em: 5 jul. 2020.

FÉLIX, Jeane. Entrevistas on-line ou algumas pistas de como utilizar bate-papos virtuais em pesquisas na educação e na saúde. In: MEYER, Dagmar Elisabeth Estermann; PARAÍSO, Marlucy Alves (org.). Metodologias de pesquisas pós-críticas em educação. 2. ed. Belo Horizonte: Mazza, 2014. p. 135-154.

FERNANDES, Vera. Mulheres de ouro: trajetória e representações de mulheres atletas de lutas. 2014. 185 f. Dissertação (Mestrado em Educação Física) - Universidade Federal de Juiz de Fora, Juiz de Fora, 2014.

FERREIRA, Heide Jancer. O percurso de mulheres como técnicas esportivas no Brasil. 2012. 93 f. Dissertação (Mestrado em Educação Física) - Universidade Federal de Viçosa, Viçosa, 2012.

FERREIRA, Heide Jancer; SALLES, José Geraldo Carmo; MOURÃO, Ludmila; MORENO, Andrea. A baixa representatividade de mulheres como técnicas esportivas no Brasil. Movimento, v. 19, n. 3, p. 103-124, 2013.

FOUCAULT, Michel. Vigiar e punir. 7. ed. Petrópolis: Vozes, 1987.

GOELLNER, Silvana Vilodre. Bela, maternal e feminina: imagens da mulher na Revista Educação Physica. 1999. 174 f. Tese (Doutorado em Educação) - Universidade Federal de Campinas, Campinas, 1999.

GOELLNER, Silvana Vilodre. Bela, maternal e feminina: imagens da mulher na Revista Educação Physica. ljuí: Editora Unijuí, 2003.

GOELLNER, Silvana Vilodre. Feminismos, mulheres e esportes: questões epistemológicas sobre o fazer historiográfico. Movimento, v. 13, n. 2, p. 171-196, maio/ago. 2007. 
GOELLNER, Silvana Vilodre. Mulher e esporte no Brasil: entre incentivos e interdições elas fazem história. Pensar a Prática, v. 8, n.1, p. 85-100, 2005.

GOELLNER, Silvana Vilodre; KESSLER, Cláudia Samuel. A sub-representação do futebol praticado por mulheres no Brasil: ressaltar o protagonismo para visibilizar a modalidade. Revista USP, n. 117, p. 31-38, abr./jun. 2018.

GOMES, Euza Maria de Paiva. A participação das mulheres na gestão do esporte brasileiro: desafios e perspectivas. 2006. 246 f. Tese (Doutorado em Educação Física) Universidade Gama Filho, Rio de Janeiro, 2006.

JAEGER, Angelita Alice; GOMES, Paula Botelho; SILVA, Paula; GOELLNER, Silvana Vilodre. Trajetórias de mulheres no esporte em Portugal: assimetrias, resistências e possibilidades. Movimento, v. 16, n. 1, p. 245-267, 2010.

KESSLER, Cláudia Samuel. Mais que barbies e ogras: uma etnografia do futebol das mulheres no Brasil e nos Estados Unidos. 2015. 375 f. Tese (Doutorado em Antropologia Social) - Instituto de Filosofia e Ciências Humanas, Universidade Federal do Rio Grande do Sul, Porto Alegre, 2015.

KILTY, Katie. Women in coaching. The Sport Psychologist, v. 20, n. 2, p. 222-234, 2006.

MINAYO, Maria Cecília de Souza. O desafio do conhecimento: pesquisa qualitativa em saúde. 10. ed. São Paulo: HUCITEC, 2007.

MONTEIRO, Igor Chagas. Mulheres de preto: trajetórias na arbitragem do futebol profissional. 2016. 130 f. Dissertação (Mestrado em Educação Física) - Universidade Federal de Juiz de Fora, Juiz de Fora, 2016.

NORMAN, Leanne. Bearing the burden of doubt: female coaches experiences of gender relations. Research Quarterly for Exercise \& Sport, v. 81, n. 4, p. 506-518, Dec. 2010.

NORONHA, Marcelo Pizarro. (Des)construindo identidades: ambiguidades, estereótipos e luta política nas relações mulher-futebol. In: KESSLER; Cláudia Samuel (org.). Mulheres na área: gênero, diversidades e inserções no futebol. Porto Alegre: Editora UFRGS, 2016. p. 175-191.

NOVAIS, Mariana Cristina Borges Novais. “À beira do gramado ou fora do jogo?”: as treinadoras do futebol de mulheres no Brasil. 2018. Dissertação. (Mestrado em Educação Física) - Universidade Federal de Juiz de Fora, Juiz de Fora, 2018.

OLIVEIRA, Gabriela Aragão Souza de; TEIXEIRA, Ana Paula de Oliveira. Trilhando um novo caminho: a gestão esportiva. Revista Gênero, v. 10, n. 1, p. 101-119, 2009.

PASSERO, Julia Gravena et al. Futebol de mulheres liderado por homens: uma análise longitudinal dos cargos de comissão técnica e arbitragem. Movimento, v. 26 p. e26060, 2020.

PFISTER, Gertrud; RADTKE, Sabine. Mulheres tomando a liderança ou mulheres tomando a liderança nas organizações esportivas alemãs. Movimento, v. 13, n. 2, p. 91-129, 2007.

PINHEIRO, Paulo Henrique. Licenciamento da CBF para clubes de futebol. Pinheiro Advogados, 2017. Disponível em: http://pinheiroadvogados.net.br/?p=300\#artigos. Acesso em: 24 jul. 2020.

PISANI, Mariane da Silva. Poderosas do Foz: trajetórias, migrações e profissionalização de mulheres que praticam futebol. 2012. 166 f. Dissertação (Mestrado em Antropologia Social) - Universidade Federal de Santa Catarina, Florianópolis, 2012. 
RAGO, Margareth. Epistemologia feminista, gênero e história. In: PEDRO, Joana Maria; GROSSI, Miriam Pilar (org.). Masculino, feminino, plural. Florianópolis: Editora Mulheres, 1998. p. 21-42.

READE, Ian; RODGERS, Wendy; NORMAN, Leanne. The under-representation of women in coaching: a comparison of male and female Canadian coaches at low and high levels of coaching. International Journal of Sports Science \& Coaching, v. 4, n. 4, p. 505-520, 2009.

RODRIGUES, Claudia Soares. Copa do Mundo na França alça futebol feminino a outro patamar. Agência Brasil, dez. 2019. Disponível em: https://agenciabrasil.ebc.com.br/ esportes/noticia/2019-12/copa-do-mundo-na-franca-alca-futebol-feminino-outro-patamar. Acesso em: 05 maio 2020.

ROMERO, Sonia Mara Thater. Gestão da diversidade de gênero nas organizações: estudo de casos múltiplos sobre homens e mulheres iguais nas desigualdades. Porto Alegre: EDIPUCRS, 2009.

SEDGWICK, Eve Kosofsky. Between men. In: HEILBRUN, Carolyn G.; MILLER, Nancy K. (ed.). Gender and culture. New York: Columbia University, 1985. p. 1-19.

SEFFNER, Fernando. Sigam-me os bons: apuros e aflições nos enfrentamentos ao regime da heteronormatividade no espaço escolar. Educação e Pesquisa, v. 39, n. 1, p. 145-159, jan./mar. 2013.

TORGA, Monique. Com a palavra, as gestoras: a trajetória de mulheres em cargos de gestão nos clubes de futebol do Brasil. 2019. 163 f. Dissertação (Mestrado em Educação Física) - Universidade Federal de Juiz de Fora, Juiz de Fora, 2019.

WERNEK, Jeremias; SALDANHA, Marinho. Renato Gaúcho dispara contra técnicos estudiosos: "Quem não sabe, estuda". Folha UOL, dez. 2016. Disponível em: https://www. uol.com.br/esporte/futebol/campeonatos/copa-do-brasil/ultimas-noticias/2016/12/08/renatogaucho-dispara-contra-tecnicos-estudiosos-quem-nao-sabe-estuda.htm. Acesso em: 25 jul. 2020. 
Abstract: Based on cultural and gender studies, this research analyzes women's representativeness as coaches and assistant coaches in women's football, seeking to identify the subversion and resistance strategies adopted for their inclusion and permanence. The analysis focused on participants' speeches and document sources such as news articles and academic works. It shows how professionals gained access to the roles resulting from their leadership experiences as athletes and/or interns and for their high capacity. They ensure their permanence by attesting their competence on a daily basis, maintaining their level of ability and overcoming gender stereotypes. They personify the eminent resistance offered by women in spaces traditionally reserved for men, thus tensioning power relations. However, the consolidation of equal conditions requires financial investment and, above all, a commitment to deconstructing gender stereotypes.

Keywords: Gender-based division of labor. Football. Women working. Stereotyped behavior.

Resumen: Fundamentada en los estudios culturales y de género, esta investigación analiza la representatividad de mujeres en cargos de entrenadora y auxiliar en el fútbol femenino, buscando identificar las estrategias de subversión y resistencia adoptadas para lograr su inserción y permanencia. Los materiales de análisis fueron los discursos de las participantes, aliados a fuentes documentales, como noticias y producciones académicas. El análisis muestra que las profesionales conquistaron su acceso a los cargos debido a sus experiencias de liderazgo como atletas y por sus altos niveles de capacitación. Aseguran su permanencia probando diariamente su competencia y superando los estereotipos de género. Encarnan la resistencia ofrecida por las mujeres en espacios tradicionalmente reservados a los hombres, tensando las relaciones de poder. Sin embargo, la consolidación de una condición de ecuanimidad requiere inversión financiera y, sobre todo, un compromiso con la deconstrucción de los estereotipos de género.

Palabras clave: División de trabajo basado en el género. Fútbol. Mujeres trabajadoras. Conducta estereotipada. 


\section{LICENÇA DE USO}

Este é um artigo publicado em acesso aberto (Open Access) sob a licença Creative Commons Atribuição 4.0 Internacional (CC BY 4.0), que permite uso, distribuição e reprodução em qualquer meio, desde que o trabalho original seja corretamente citado. Mais informações em: http://creativecommons.org/licenses/by/4.0

\section{CONFLITO DE INTERESSES}

Os autores declararam que não existe nenhum conflito de interesses neste trabalho.

\section{CONTRIBUIÇÕES AUTORAIS}

Mariana Cristina Borges Novais: Conceptualização; Curadoria de dados; Análise formal; Investigação; Metodologia.

Ludmila Mourão: Conceptualização; Análise formal; Metodologia; Recursos; Supervisão.

Osmar Moreira de Souza Junior: Análise formal; Metodologia; Recursos.

Igor Chagas Monteiro: Validação; Visualização; Redação - revisão e edição.

Bárbara Aparecida Bepler Pires: Validação; Visualização; Redação - revisão e edição.

\section{FINANCIAMENTO}

O presente trabalho foi realizado com apoio da Coordenação de Aperfeiçoamento de Pessoal de Nível Superior - Brasil (CAPES) - Código de Financiamento 001. This study was financed in part by the Coordenação de Aperfeiçoamento de Pessoal de Nível Superior - Brasil (CAPES) - Finance Code 001.

\section{ÉTICA DE PESQUISA}

O projeto de pesquisa foi encaminhado e aprovado pelo Comitê de Ética em Pesquisa da Universidade Federal de Juiz de Fora, n. protocolo 1.947.687.

\section{COMO REFERENCIAR}

NOVAIS, Mariana Cristina Borges; MOURÃO, Ludmila; SOUZA JUNIOR, Osmar Moreira de; MONTEIRO, Igor Chagas; PIRES, Bárbara Aparecida Bepler.

Treinadoras e auxiliares do futebol de mulheres no brasil: estratégias de subversão e resistência no campo da liderança esportiva. Movimento (Porto Alegre), v.27, p. e27023, jan./dez. 2021. Disponível em: https://seer.ufrgs.br/Movimento/ article/view/106782. Acesso em: [dia] [mês abreviado]. [ano]. DOI: https://doi. org/10.22456/1982-8918.106782.

\section{RESPONSABILIDADE EDITORIAL}

Alex Branco Fraga*, Elisandro Schultz Wittizorecki*, Ivone Job*, Mauro Myskiw*, Raquel da Silveira*

*Universidade Federal do Rio Grande do Sul, Escola de Educação Física, Fisioterapia e Dança, Porto Alegre, RS, Brasil. 


\section{ERRATA}

No artigo "TREINADORAS E AUXILIARES DO FUTEBOL DE MULHERES NO BRASIL: SUBVERSÃO E RESISTÊNCIA NA LIDERANÇA ESPORTIVA", com número de DOI: 10.22456/1982-8918.106782, publicado no periódico Movimento, 27(1):e27023, na página 1:

Onde se lia:

"Bárbara Aparecida Beples Pires"

Leia-se:

"Bárbara Aparecida Bepler Pires" 